\title{
Randomization Book Entry Position Number
}

National Cancer Institute

\section{Source}

National Cancer Institute. Randomization Book Entry Position Number. NCI Thesaurus.

Code C94037.

An integer specifying the value of a numerical sequence for a Stratum Group that should be used to assign a subject to an arm or a portion of an arm. 